\title{
Discussion on the Creation of Watercolor Painting in Practical Teaching in Colleges and Universities
}

\author{
Derui Kang \\ Huanghe Science and Technology College \\ Zhengzhou, Henan, China 450063
}

\begin{abstract}
In improving the quality of works and the role of watercolor painting in creation teaching, if we want to avoid divergence between life and creation, singleness of performance language, lack of ideological connotation and its own characters as well as working tendency, we must go deeply into life in creative teaching and experience life totally to assimilate and refer to the essence of other arts to enrich the language and performance skills of watercolor painting and value ideological connotation of works. Only in this way can we improve art taste and teaching quality of watercolor painting better and more comprehensively.
\end{abstract}

Keywords-watercolor painting creation; art creation; real life; watercolor art

\section{INTRODUCTION}

History of watercolor in China is not long. It just has lasted for less than a century. Because it conforms to the Chinese natural and unrestrained aesthetic psychology, it comes in to being soon. The Chinese watercolor painting got its development and prosperity on the basic of hard exploration and efforts of several generations of painters. From current content of watercolor painting works and painter's point of view, there are four tends on the artistic ideas and creative behaviors: the first is inheriting traditional British watercolor painting basis; the second is pure self-awareness or blundering fanatical creation tendency. The Chinese watercolor painting has developed rapidly in recent two decades, but there are still many painters paying attention to the skill research and addicting to their unique characteristics like sprightliness, softness and mellifluence, which leads to bad conditions in creating watercolor painting.

For years, Chinese watercolor art has only existed some opuscular and few masterpieces acting in deep and strong artistic appeal. Over time, a lot of watercolor painter would think watercolor painting creations are mainly still life, landscapes and figures sketch and the creation is also relative. Owning to such thoughts, there are some strange phenomena: first, they consider that watercolor painting is not suitable for creation and large works performed profoundly. Second, creation equals copying pictures. Third, more and more watercolor painting beginners are trapped in skill frame and prefer to deal with performance effects. To get rid of these strange phenomena and revitalize the creation of watercolor painting, the author considers that the painters should notice below two aspects: realizing the development history of watercolor painting correctly and cultivating creative thinking.

\section{REALIZING THE DEVELOPMENT HISTORY OF WATERCOLOR PAINTING CORRECTLY}

Western modern watercolor painting came into being in 16th century. From German painting master Albrecht Dürer, he is good at painting animals, plants and scenery by laying a watercolor foundation then painting with gouache; Rubens painted watercolor sketches by applying the method of light and shade; Rembrandt painted light color on the sketch in the picture. French painter Delacroix and Spanish painter Goya also painted poetic landscapes or portraits by watercolor painting tools in 18th and 19th centuries. Analyzing works of painters in this period we can easily find that: first, watercolor painting is amateur and takes little time. Second, picture contents are mainly scenery, still life sketch and portrait and works have no theme, they are just the preliminary sketch for oil painting. Third, manifesting simulating effect of oil painting by tools and materials of watercolor painting; fourth, picture scale is small; fifth, ignoring watercolor painting language while valuing oil painting language. Therefore, watercolor painting didn't become an independent type in this period.

In the 19th century, watercolor painting became independent in Britain thanks to the efforts of some painters. They realized distinctive art effects of watercolor painting and innovated tools and materials to form a series of watercolor creation skills, making watercolor painting develop unprecedentedly and emerging a lot of famous watercolor painters such as Tyner, John Constable, and Richard Parkes Bonington. But the state of watercolor painting is not equal to oil painting from beginning to end. Painters of that time prefer the aesthetic value of oil painting and economic value of wood block so they have bias on watercolor painting, which has bad effect on the development of watercolor painting. Therefore, in 19 th century, there are more and more watercolor painters in Britain but fewer focused on it. Many printers worked on oil painting, wood block and wall painting then took watercolor painting as a part-time job. This influenced the art quality of watercolor painting undoubtedly. For example, the materials of watercolor painting are limited and mainly are scenery; the works are lack of theme and can't play the social effects of watercolor painting. 
Watercolor painting is just one form of painting. Its existence and energy are manifested by artistic practices and abilities in artistic production. Realizing the development of watercolor printing correctly can help us understand that, the sketch theory of watercolor printing is based on people's insufficiency understanding and deviation of watercolor painting at a certain stage, it is also based on the drawback because of the lack of expressive ability and creative ability. They emphatically summed up in the small carrier energy of watercolor painting and unilaterally thought that watercolor painting is just only sketch and is not suitable for creation. As a matter of fact, the materials and contents of watercolor painting and the scale and style are decided by the creative thinking of painters but not by the painting itself. Therefore, people working on watercolor painting should cultivate creative thinking.

As a part of art education in colleges and universities, on one hand, watercolor painting bears the responsibility of imparting professional knowledge and skills, on the on the hand, it serves to quality education centered on promoting people ' s overall development. Therefore, the positioning of contemporary watercolor teaching is to cultivate students with watercolor creation thinking and to enable students to master the watercolor language thinking mode and the basic rule of painting. (1) some relevant textbooks would put forth the importance of cultivating students' creative thinking. But in practical teaching, these goals and importance are not highlighted. In author's eyes, the reasons for this are some disadvantages of watercolor painting in teaching. These disadvantages prevented achieving teaching goals in large extent. They kept students from creative ability and innovative ability. Therefore, reforming watercolor painting teaching to achieve the dominant teaching goal of cultivating students' innovative ability is necessary.

Art creation is a compulsory course for students majoring in arts before graduation and it helps the comprehensive training and improvement of student on overall artistic quality.

According to current conditions of colleges and universities, we can find reasons: students have different cognitions of life, different understanding to the essence of art and different aesthetic concepts and creative experience, so they are deprived from life in creation, create by imagination without basis, their performance skills are modeled and the theme is feeble and futile. To solve these problems, we must stress and value the following three aspects:

\section{EXPERIENCING AND PERCEIVING REAL LIFE}

As is known to all, beauty lies in our life all the time. All the excellent works of ancient and modern times are from real life and artists' deep understanding to real life and emotion accumulation. Throughout the ages, a Chinese saying that means combining theory with practices has been the only way for painters to create from life and the solid steps for success. Therefore, there are extremely vivid contents in colorful life, which is the inexhaustible source for art creation.

Life reflected by art works is higher and more typical than real life. When painters came out of painting room, came back to life and nature and something moved them deeply, they would be motivated in feeling so that they wanted to create strongly. The following is that they would face many materials, so they have to decide and analyze to choose and select the essential to sublime arts. After highly generalization, extraction and processing, they would reach the highest state of creation-inspiration. Only such creation can be thrilling and distinctive from others, can be called mater piece and have individuality and vitality of art.

Hegel said : "artists should not only see more in the world, and be familiar with external and internal phenomena, but also ruminate many important things in heart and be moved by them deeply, got many experiences and rich life and then be able to manifest truly profound things in life in detail". These words can show Hegel's deep observation of art and declare that art creation is advanced, complicated and special spiritual activity of humanity. The thrilling masterpieces such as sketch bloodstained garment of Wang Shikuo and the oil painting father of Luo Zhongli and so on are all authors' deep understandings to life and results of accumulation, extraction and processing, which fully proved that life is the mother of arts. Andrew Wyeth, an American famous Watercolor art master, in his works runs over enchanting poetic illusion. The reason why his works strongly shakes the souls of people is closely related to the deepness of life dug by author and art passion in transmitting pictures and unique artistic feelings.

Therefore, in teaching of art creation, teachers should make students establish correct creative value and lead them to love life, go deeply into life to experience, cognate, feel and realize life clearly, constantly dig out and find the beauties in real life, put real emotion and feeling of life into works and avoid subjective imagination in creation. Only in this way can we make the art creation develop well in practical teaching in colleges and universities.

\section{LEARNING TO REFERENCE AND FUSION}

The creation of watercolor arts should not be limited in traditional performance skills because these skills are not enough for creation. We should depend on art traditions of eastern and western cultures as well as inherit, assimilate, refer to and fuse the essence of other painting arts. Tradition is a cultural factor that we pass down from generation to generation. It is not just the thought behavior and one of art forms, but a common mental habit. Of course, there are both essence and terrible habits in tradition.

Because of this, we need to absorb the quintessence and apply it to watercolor arts. The watercolor arts have developed for more than one hundred years. It is also the history of constant innovation, advance, sublimation and integration on the basis of traditions of eastern and western cultures as well as inheriting, assimilating, referring to and fusing the essence of other painting arts.

At the same time, in the creation of watercolor painting, we should also refer to the methods, art language and performance skills of oil painting, Chinese painting and folk arts. We should neither stick to the original model of watercolor art nor imitate 
methods, art language and performance skills of other paintings blindly.

So, in the creation of watercolor painting, especially inheriting, assimilating, referring to and fusing excellent painting traditions of home and abroad and other arts we should not simply imitate and joint them into watercolor painting, but should give it new vitality and artistic connotation and charming by grafting, digestion and reconstruction to make it achieve more. In creative teaching, we should take correct and flexible ways to enlighten, guide and encourage students, this will be of vital importance in widening students' thoughts, referring and fusing widely and exploring and innovating bravely to improve and enrich individual language of watercolor painting.

\section{FOCUSING ON THE CONNOTATION OF WORKS}

Watercolor arts in real life are commendable. If we addict to the form interest, the development of the arts will be uncompleted and unpromising. A good watercolor painting should be the product of superb painting skills and highly spiritual connotation. It should be the reflection and expression of true feelings to life and society. The material, contents, theme and thought reflected by works as well as the scale, style and skills are all decided by ideology, art concept and expressive ability of the author.

Art comes from life. It is a special form of human selfconsciousness and the observation and introspection to humanity.

\section{CONCLUSION}

All in all, our feeling expressions for real life, the variety of language arts performance and spiritual connotation of excellent works should be closely concerned in the reaction and practical teaching of watercolor painting in colleges and universities. Only in this way can we improve the art level and teaching quality of watercolor painting better and more comprehensively.

\section{REFERENCES}

[1] Wu Yongqiang. Xifang meishushi.(Western Fine Art History) [M].Hunan Fine arts publishing house, 2006.

[2] Watercolor painting art committee of Chinese artists association, Journal of Chinese watercolor series -- Chinese watercolor (11). Guangxi: Guangxi fine arts publishing house. Sept, 1999

[3] Lawrence .C. Goldsmith. Watercolor Creation Examples. Guangxi: Guangxi fine arts publishing house. May, 1999

[4] Lv Zhikai. Watercolor masters teaching you painting. Hubei Fine Arts Publishing House, 2002

[5] Liu Mingyi, British watercolor painting history. Shanghai People's Fine Arts Publishing House, 1985.

[6] Bai Chonglu. Reference and Development. [J].watercolor arts, Apr,1995.

[7] Huang Tieshan. A brief discussion on the skills of watercolor painting. Art Guide. Jun,1996.

[8] Gu Senyi. On the artistic Value of Modern Watercolor Art. Journal of nanjing art institute (fine art and design), Mar,2005. 